\title{
Traumatic Brain Injury: Persistent Misconceptions and Knowledge Gaps Among Educators
}

\author{
Deborah Ettel \\ Eugene School District 4J \\ Ann E. Glang, Bonnie Todis \\ University of Oregon \\ Susan C. Davies \\ University of Dayton
}

\begin{abstract}
Each year approximately 700,000 U.S. children aged 0-19 years sustain a traumatic brain injury (TBI) placing them at risk for academic, cognitive, and behavioural challenges. Although TBI has been a special education disability category for 25 years, prevalence studies show that of the 145,000 students each year who sustain long-term injury from TBI, less than $18 \%$ are identified for special education services. With few students with TBI identified for special education, TBI is mistakenly viewed as a low-incidence disability, and is covered minimally in educator preparation. We surveyed educators and found that they lacked knowledge, applied skills, and self-efficacy in working with students with TBI. While those with special education credentials and/or additional training scored significantly higher than general educators, all demonstrated inadequate skills in working with students with TBI. This finding suggests that teachers, especially those in general education, have misconceptions and knowledge gaps about TBI and its effects on students. Misconceptions have led to the misidentification and under-identification of students with TBI, leaving this group of students with disabilities potentially underserved. To meet the academic and behavioural needs of students with TBI, all educators need effective training in working with students with TBI.
\end{abstract}


Each year approximately 700,000 U.S. children aged 0-19 years sustain a traumatic brain injury (TBI) requiring hospitalization or emergency treatment (Faul, Xu, Wald, \& Coronado, 2010). Children with TBI are at risk for a range of challenges that impair academic performance and their transition to post-secondary education and employment (Anderson, Catroppa, Morse, Haritou, \& Rosenfeld, 2009; Beauchamp et al., 2011; Catroppa \& Anderson, 2007; Chapman et al., 2010; Ganesalingam et al., 2011; GerrardMorris et al., 2010; Kurowski et al., 2011; Yeates et al., 2005). Children with moderate to severe injuries are likely to have cognitive, behavioural, and social difficulties that affect their long-term quality of life (Rivara, Vavilala, et al., 2012). Even mild injuries to the developing brain (i.e., concussion) can result in persistent neural alterations (Eisenberg, Andrea, Meehan, \& Mannix, 2013; Rivara, Koepsell, et al., 2012; Walz, Cecil, Wade, \& Michaud, 2008) that significantly affect social and educational functioning (Sesma, Slomine, Ding, McCarthy, \& the Children's Health After Trauma Study Group, 2008).

\section{Effects of TBI on School Performance}

Although students with TBI share some characteristics with students with other disabilities, the unpredictable mix of cognitive, behavioural, and social impairments associated with TBI are unfamiliar to most teachers (Glang et al., 2015). Inconsistent learning profiles, knowledge gaps, and lack of self-awareness pose particular challenges in the classroom setting (Farmer, Clippard, \& Luehr-Wiemann, 1996; Farmer \& JohnsonGerard, 1997; Glang, Sohlberg, \& Todis, 1999; Telzrow, 1987; Ylvisaker \& Feeney, 1998). Impairment of executive functioning, attention, concentration, and processing speed following TBI also contribute to academic difficulties (Halstead et al., 2013; Iverson, Brooks, Collins, \& Lovell, 2006; Moser, Schatz, \& Jordan, 2005); and up to a third of students with TBI also develop behavioural or psychological symptoms (Barlow et al., 2010; Rimel, Giordani, Barth, Boll, \& Jane, 1981; Willer \& Leddy, 2006; Yeates, 2010). Because many teachers are unaware of the effects TBI can have on behaviour, behaviour problems are often misdiagnosed as premorbid rather than being appropriately linked to the TBI (Clark, Russman, \& Orme, 1999).

TBI at any point during childhood can disrupt normative development, contributing to subsequent deficits in performing age-appropriate functions. Children who sustain injuries in infancy and early childhood often have significant skill deficits and poor longterm outcomes that might not be recognized as consequences of their injury. Although students injured in adolescence often recover many of the academic skills and knowledge acquired before the injury, they are likely to have difficulty learning new material and developing higher order reasoning, organizational, and social skills (Anderson \& Catroppa, 2005; Anderson, Catroppa, Morse, Haritou, \& Rosenfeld, 2005).

\section{TBI Identification Rates}

Of the 700,000 yearly childhood (ages 0-19) TBIs that require hospitalization, prevalence studies (Zaloshnja, Miller, Langlois, \& Selassie, 2008) report that approximately 145,000 cases result in a long-term or lifelong TBI-related disability. The number of students enrolled in the TBI category of special education is 26,000 (U.S. Department of Education National Center for Education Statistics, 2015), indicating that 
fewer than $18 \%$ of students who likely need services are receiving them. Special education identification rarely occurs after the first year post-injury, so children with early injuries or emerging problems are unlikely to be identified (Taylor et al., 2003). When academic and behaviour problems become evident years later, they are likely to be linked to specific learning disability (SLD) or behaviour disorders, rather than TBI. In a recent survey, most state special education directors reported that students with TBI are not appropriately identified in their states, and fewer reported a TBI specialist within the state education agency than in 1999 (Glang, Todis, Ettel, \& Yeates, 2013).

Misidentification of TBI as another disability can contribute to incomplete or inappropriate assessment and resultant support services. Unlike some other disabilities, the recovery process for students with TBI is often dynamic, requiring frequent monitoring and program adjustment; some sequelae may not fully appear until long after the injury is forgotten. The student with TBI may have underlying vision, sensory, gait, mood, or fatigue issues that may go unaddressed because of misidentification or lack of awareness. Further, the social-emotional needs of a student (and family) recovering from brain injury are typically very different from those of a student with a lifelong learning disability. Unlike most disabilities, with TBI there is a "before" and "after." Consider the differences between a once high-achieving, socially adept student whose post-TBI status is suddenly significantly impaired and the student with a longstanding learning or behaviour disorder. While under-identification of TBI clearly has costs, so, too, does misidentification (Dyches \& Prater, 2010).

Failure to provide appropriate educational services to students with TBI could be due in part to lack of teacher knowledge and skills (Todis \& Glang, 2008; Todis, Glang, Bullis, Ettel, \& Hood, 2011). Surveys of speech-language pathologists (Evans, Hux, Chleboun, Goeken, \& Deuel-Schram, 2009), school psychologists (Hooper, 2006), and teachers (Davies, Fox, Glang, Ettel, \& Thomas, 2013) reveal limited training in assessment and intervention with TBI, suggesting inadequate preparation across professions. A recent survey of teachers in the United Kingdom also demonstrated this lack of preparation, and suggested that teachers hold misconceptions about TBI, which may adversely affect the child's school experience (Linden, Braiden, \& Miller, 2013). A recent survey of state directors of special education showed that state leaders believe their annual TBI student counts are inaccurate; more than a quarter of those indicate that the inaccuracy was significant (Glang et al., 2015). One of the main reasons given for that inaccuracy was lack of teacher awareness about TBI as a disability (e.g., teachers not understanding the long-term consequences of TBI and parents' and professionals' unfamiliarity with the characteristics of students with brain injury, the definitions used by schools, and the consequences of injury on school performance). Another reason state directors gave for the inaccuracy was misidentification of students with TBI. State directors reported that in only $40 \%$ of cases were students with TBI identified under the category of TBI; students with TBI were more often identified under the categories of SLD, other health impairment, emotional disturbance, and others, or not identified at all (Glang et al., 2015).

Furthermore, a recent analysis of ten university textbooks revealed that TBI is minimally discussed in current special education texts (Ettel, McCart, \& Glang, 2014). Of the approximately 500 pages in each text, only an average of 9.8 pages contained 
information about TBI. Only one of the top ten most widely used special education texts (Turnbull, Turnbull, Wehmeyer, \& Shogren, 2013) devoted a chapter specifically to TBI, although in the United States TBI has been an Individuals with Disabilities Education Act (IDEA) disability category since 1990. All ten books had a specific chapter on autism spectrum disorder, and several included a chapter on attention deficit-hyperactivity disorder, which is not a disability category. Thus, the limited coverage of TBI in teacher preparation texts supports state special education directors' perception that educators lack awareness of TBI - the core texts on disabilities only minimally address TBI compared to other disability categories.

The purpose of the present study was to assess educator knowledge, skills, and selfefficacy related to TBI in a sample of teachers currently working in public schools.

The study's research questions were:

1. What are the current levels of teacher knowledge and skill application in working with students with TBI?

2. How do teachers rate their ability to work effectively with students with TBI (self-efficacy)?

3. Which teacher characteristics predict knowledge, skills, and self-efficacy in working with students with TBI?

\section{Methods}

\section{Participants}

We recruited participants through print and online advertising on LDOnline, a website that targets general and special education teachers working with students with learning disabilities. Potential participants accessed an online screening tool by clicking a link on the website. A total of 352 teachers participated in the survey. Most of the teachers were from the United States (82\%), were special education teachers $(62 \%)$, and had obtained a master's degree or greater $(75 \%)$. Respondents included preschool through high school teachers, and the sample was evenly distributed across the grades. Twenty-five percent of the sample indicated they had taught for 26 or more years. About one third had taught for 1-10 years, and another third had taught for 11-25 years. In addition, about one third of the respondents $(33 \%)$ indicated that they had worked with 1-5 students with TBI, and more than half (55\%) indicated that they had previously worked with 6-10 students with TBI. Only about one quarter of the teachers said that they had prior training in working with students with TBI, but almost all said that they had worked with at least one student with TBI ( $85 \%$ worked with 1-10 students with TBI).

\section{Instruments}

TBI knowledge. The TBI Knowledge Survey was adapted from a validated instrument (Hux, Bush, Evans, \& Simanek, 2013; Hux, Walker, \& Sanger, 1996), with additional items derived from TBI training materials (Dise-Lewis, Lewis, \& Reichardt, 2009; Glang, Tyler, Pearson, Todis, \& Morvant, 2004). The final 30-item adapted version for the current study (see Appendix) included a four-point response option (true, 
probably true, probably false, and false). For scoring, responses were combined to form two categories, true-probably true and false-probably false. The number of correct items was summed and a percentage correct computed.

TBI skill application and self-efficacy. TBI skill application-knowledge application-was assessed with four scenarios depicting classroom situations involving students with TBI. Each scenario was assessed with a six-point scale (would never respond this way, fairly unlikely, not very likely, somewhat likely, fairly likely, and very likely to respond this way). The responses fairly likely to respond this way and very likely to respond this way were combined and scored as correct in response to the correctly handled scenarios. Likewise, the responses fairly unlikely to respond this way and would never respond this way were combined and scored as correct in response to the incorrectly handled scenarios. A total score of number of correct responses was computed. Because self-efficacy is theoretically linked to behaviour change (Ajzen, 1991; Ajzen, Joyce, Sheikh, \& Gilbert Cote, 2011), survey items also assessed this construct with the same four scenarios (e.g., "How confident are you that you could successfully handle a situation like this?") using a six-point scale ( 1 = not at all confident, $6=$ completely confident; alpha $=.82$ ).

A copy of the teacher survey appears in the Appendix.

\section{Procedures}

The evaluation was conducted over Survey Console, a secure server on the Internet. When potential participants accessed the link provided in the study advertisements, they were taken directly to the survey and given a unique identifier access number. For participating in the study, participants were offered a chance to win one of five $\$ 200$ cash awards.

\section{Data Analysis}

We used independent t-tests and one-way ANOVA models with Scheffé follow-up tests to examine whether TBI knowledge, skill application, and self-efficacy differed by the following teacher characteristics: (a) current area of teaching, (b) special education license held, (c) history of TBI training, (d) years of teaching experience, and (e) number of students with TBI worked with in a school setting. We provide Cohen's d-statistic (Cohen, 1988) as a measure of effect size following the convention of $d=.2$, small; $d=.5$, medium; and $\mathrm{d}=.8$, large effects.

\section{Results}

The average TBI knowledge score across all teachers was $55.9 \%$ ( $\mathrm{SD}=9.8$, range 26.6-80.0). Three statistically significant differences in TBI knowledge scores by teacher characteristics appeared. Special education teachers had significantly higher knowledge scores than general education teachers (56.8 vs. 54.3$)$, a moderately small effect $(\mathrm{d}=$ .25); teachers with a history of TBI training had significantly higher knowledge scores than teachers without training (58.4 vs. 55.1), a moderately small effect $(\mathrm{d}=.34)$; and years of teaching experience was significantly related to knowledge scores, a moderately 
small effect $(\mathrm{d}=.37)$. Follow-up Scheffé contrasts found no categories of years of teaching that statistically differed at $\mathrm{p}<.05$.

The average TBI skill application score across all teachers was $72 \%(8.6 / 12$ [SD $=$ 2.1, range 0-12]). We found two statistically significant differences in TBI skill application scores by teacher characteristics (Table 1). Special education teachers had significantly higher TBI skill application scores than general education teachers (8.9 vs. $8.3)$, a moderately small effect $(\mathrm{d}=.31)$, and teachers who held a special education license had significantly higher TBI skill application scores than those who did not have a license ( 8.8 vs. 8.3$)$, a small effect $(\mathrm{d}=.24)$.

Table 1

TBI Applied Skills Scores by Teacher Characteristics

\begin{tabular}{lrrrrr}
\hline & Mean & SD & Test Statistic & p-value & Effect size \\
\hline $\begin{array}{l}\text { Current area of teaching } \\
\quad\end{array}$ & 8.25 & 2.12 & & .006 & .31 \\
$\quad$ General education & 8.88 & 1.99 & & & \\
$\quad$ Special education & & & $\mathrm{t}(350)=0.57$ & .566 & .07 \\
History of TBI training & 8.61 & 2.13 & & & \\
$\quad$ No & 8.76 & 1.91 & & & \\
$\quad$ Yes & & & $\mathrm{F}(5,346)=0.86$ & .507 & .22 \\
Years of teaching experience & 8.41 & 1.91 & & & \\
0-5 years & 8.62 & 1.99 & & & \\
6-10 years & 9.11 & 2.04 & & & \\
11-15 years & 8.48 & 1.89 & & & \\
16-20 years & 8.68 & 2.46 & & & \\
21-25 years & 8.51 & 2.06 & & & \\
26 or more years & & & $\mathrm{F}(3,347)=0.50$ & & \\
No. of TBl students & 8.52 & 2.26 & & & \\
0 & 8.73 & 1.96 & & & \\
1-5 & 8.36 & 2.26 & & & \\
6-10 & 8.93 & 1.79 & & \\
More than 10 &
\end{tabular}

$\mathrm{TBI}=$ traumatic brain injury, $\mathrm{SD}=$ standard deviation, Effect size $=$ Cohen's d-statistic

The average TBI self-efficacy score across all teachers was 4.8 on a scale of $0-6$ (SD $=0.7$, range $1.5-6.0)$. We found three statistically significant differences in self-efficacy score by teacher characteristic (Table 2). Special education teachers had significantly higher self-efficacy scores than general education teachers (4.9 vs. 4.6), a moderately small effect $(\mathrm{d}=.41)$; teachers who held a special education license had significantly higher selfefficacy scores than those who did not have a license (4.8 vs. 4.6), a moderately small effect $(\mathrm{d}=.37)$; and the number of TBI students taught was significantly related to selfefficacy scores, a moderately small effect $(\mathrm{d}=.36)$. Follow-up Scheffé contrasts found that teachers who had never taught a student with TBI had significantly lower scores than teachers who had taught more than 10 students with TBI (4.6 vs. 5.1). 
Table 2

TBI Self-Efficacy Scores by Teacher Characteristics

\begin{tabular}{|c|c|c|c|c|c|}
\hline & Mean & SD & Test Statistic & p-value & Effect size \\
\hline Current area of teaching & & & $t(348)=3.73$ & $<.001$ & .41 \\
\hline General education & 4.59 & 0.69 & & & \\
\hline Special education & 4.85 & 0.63 & & & \\
\hline SPED license held & & & $t(349)=3.21$ & .001 & .37 \\
\hline No & 4.59 & 0.69 & & & \\
\hline Yes & 4.83 & 0.64 & & & \\
\hline History of TBI training & & & $t(349)=1.46$ & .082 & .18 \\
\hline No & 4.72 & 0.66 & & & \\
\hline Yes & 4.84 & 0.67 & & & \\
\hline Years of teaching experience & & & $F(5,345)=0.33$ & .895 & .14 \\
\hline $0-5$ years & 4.82 & 0.68 & & & \\
\hline $6-10$ years & 4.69 & 0.59 & & & \\
\hline $11-15$ years & 4.80 & 0.65 & & & \\
\hline $16-20$ years & 4.70 & 0.68 & & & \\
\hline $21-25$ years & 4.73 & 0.64 & & & \\
\hline 26 or more years & 4.77 & 0.73 & & & \\
\hline No. of TBI students & & & $F(3,346)=3.78$ & .011 & .36 \\
\hline 0 & 4.61 & 0.73 & & & \\
\hline $1-5$ & 4.80 & 0.62 & & & \\
\hline $6-10$ & 4.78 & 0.57 & & & \\
\hline More than 10 & 5.11 & 0.76 & & & \\
\hline
\end{tabular}

\section{Discussion}

The results of this survey suggest that during the 25 years since TBI became a disability category under IDEA ("Individuals with Disabilities Education Act," 1990), teacher preparedness to work with students with TBI has not changed significantly. Although special education teachers in our sample scored significantly higher than general education teachers on knowledge of TBI, the knowledge scores for both groups were below $60 \%$. If a minimum criterion for competence is $70 \%$ correct - a $C$ gradeteachers (both general education and special education) earned an $F$. Hooper (2006) reported similar rates of knowledge about TBI among school psychologists in two states and in a sample of special education teachers in several states. In Hux's (1996) study, $20 \%$ of special education teachers were unaware that TBI was even an eligibility category for services (Glang et al., 2008).

In applied skills, teachers fared better, with an average of $72 \%$ on application of appropriate instruction and intervention. However, it could be that on this skills measure, despite a lack of specific TBI training, teachers applied their skills in working with all students with disabilities or learning challenges to the scenarios. 
We also found that greater knowledge of TBI is associated with years of teaching experience and that working with 10 or more students with TBI across a teaching career increased the ratings of self-efficacy. But the only significant difference was between those who had never taught a student with TBI and those who had taught 10 or more, and neither case is typical. Although it is logical that knowledge and self-efficacy would improve with hands-on experience over the years, trial-and-error is not the most efficient path for teachers to gain expertise with students with TBI. They-and the students they serve-deserve competent support.

Teachers with more training demonstrated greater knowledge and applied skills and reported greater self-efficacy than teachers with less training. This finding echoes the recent assertion by state directors of special education that teachers' lack of awareness of TBI is a main cause of inaccurate identification of students with TBI, a finding further reinforced by the limited coverage of TBI as a disability in teacher preparation textbooks.

Training in special education was associated with increased levels of knowledge, TBI skills, and self-efficacy in working with students with TBI. However, since most students with TBI are not identified for special education (U.S. Department of Education National Center for Education Statistics, 2015; Zaloshnja et al., 2008), they are in many cases served by teachers who are unprepared to work effectively with them. This finding suggests that increased rates of special education identification among students with TBI would provide them with the best opportunity to work with teachers who are at least somewhat prepared to meet their specific needs

Increasing TBI training for all teachers might also address the issue of misidentification of students with TBI under alternate eligibility categories. Misidentification contributes to under-identification, leading to a misperception that TBI is a low-incidence disability that few teachers will encounter in their classrooms. This misperception in turn leads districts and states, as well as teacher preparation programs, to underestimate the need for training and research in TBI. Accurate identification would increase the visibility of students with TBI and increase the likelihood that those students would receive appropriate support services. Accurate identification will not be possible, however, without increased teacher knowledge and skills in TBI. Increased awareness of TBI is the key to correcting the downward spiral that characterizes current educational practices for students with TBI.

\section{Limitations}

The survey participants represent a convenience sample, a nonprobability sample with inherent biases. While cost effective, this nonrandom sampling method leaves doubts about the extent to which results may be generalized to the larger population. Further, the use of a closed (as opposed to an open-ended) response system of measurement in our scenario questions may have inaccurately captured the extent of teacher knowledge.

In this study, teacher ratings of self-efficacy served as a proxy for their skill in meeting the needs of students with TBI. Teachers with higher self-efficacy have been found to show more support and provide a more positive classroom environment than those with lower 
self-efficacy, and their students showed stronger literacy skills (Guo, Connor, Yang, Roehrig, \& Morrison, 2012). Observational studies comparing delivery of services by trained and untrained teachers would provide a more accurate assessment of teacher skill in instruction and behaviour management. However, because the ultimate goal of assessing teacher preparedness is to gauge teachers' ability to effect positive student change, a randomized study comparing student outcomes under different teaching conditions would provide the most accurate assessment of the effects of different levels of teacher knowledge and awareness on teacher behaviour and its effects on students with TBI. But the feasibility of such a study is limited by ethical, procedural, and financial considerations.

\section{Conclusion}

The goal of special education is to provide services to students that make it possible for them to achieve their full potential. Achieving that goal requires teachers who have the awareness, knowledge, and skills to work effectively with each student, regardless of disability condition. Currently, many students with TBI do not have access to special education services, which suggests not only that assessment and identification practices should be improved, but also that both general and special education teachers need to be prepared to work with this population.

This survey suggests that teachers, especially those in general education, have some basic misconceptions and knowledge gaps about TBI and the effects of brain injury on students in their classrooms, the consequences of which are not minor. Misconceptions have led to the misidentification and under-identification of students with TBI for special education, leaving this group of students with disabilities potentially mis-served and underserved. To meet the academic and behavioural needs of students with TBI, all teachers need effective training, pre-service and in-service, in methods that have been validated with students with TBI and in adapting strategies validated with students with other disabilities to students with TBI (Dettmer, Ettel, Glang, \& McAvoy, 2014; Glang, Todis, Sublette, Eagan-Brown, \& Vaccaro, 2010; Ylvisaker et al., 2005; Ylvisaker et al., 2001). That was the expectation and promise of IDEA in 1990 when TBI became a disability category.

\section{References}

Ajzen, I. (1991). The theory of planned behavior. Organizational Behavior and Human Decision Processes, 50, 179-211.

Ajzen, I., Joyce, N., Sheikh, S., \& Gilbert Cote, N. (2011). Knowledge and the prediction of behavior: The role of information accuracy in the theory of planned behavior. Basic and Applied Social Psychology, 33, 101-117.

Anderson, V., \& Catroppa, C. (2005). Recovery of executive skills following paediatric traumatic brain injury (TBI): A 2 year follow-up. Brain Injury, 19(6), 459-470. doi:10.1080/02699050400004823

Anderson, V., Catroppa, C., Morse, S., Haritou, F., \& Rosenfeld, J. (2005). Attentional and processing skills following traumatic brain injury in early childhood. Brain Injury, 19(9), 699-710. doi:10.1080/02699050400025281 
Anderson, V., Catroppa, C., Morse, S., Haritou, F., \& Rosenfeld, J. V. (2009). Intellectual outcome from preschool traumatic brain injury: A 5-year prospective, longitudinal study. Pediatrics, 124(6), 1064-1071. doi:10.1542/peds.2009-0365

Barlow, K. M., Crawford, S., Stevenson, A., Sandhu, S. S., Belanger, F., \& Dewey, D. (2010). Epidemiology of postconcussion syndrome in pediatric mild traumatic brain injury. Pediatrics, 126(2), 374-381. doi:peds.2009-0925 [pii] 10.1542/peds.2009-0925

Beauchamp, M., Catroppa, C., Godfrey, C., Morse, S., Rosenfeld, J. V., \& Anderson, V. (2011). Selective changes in executive functioning ten years after severe childhood traumatic brain injury. Developmental Neuropsychology, 36(5), 578-595. doi:10.1080/87565641.2011.555572

Catroppa, C., \& Anderson, V. (2007). Recovery in memory function, and its relationship to academic success, at 24 months following pediatric TBI. Child Neuropsychology, 13(3), 240-261.

Chapman, L. A., Wade, S. L., Walz, N. C., Taylor, H. G., Stancin, T., \& Yeates, K. O. (2010). Clinically significant behavior problems during the initial 18 months following early childhood traumatic brain injury. Rehabilitation Psychology, 55(1), 48-57. doi:10.1037/a0018418

Clark, E., Russman, S., \& Orme, S. (1999). Traumatic brain injury: Effects on school functioning and intervention strategies. School Psychology Review, 28, 242-250.

Cohen, J. (1988). Statistical power analysis for the behavioral sciences (2nd ed.). Hillsdale, NJ: Erlbaum.

Davies, S., Fox, E., Glang, A., Ettel, D., \& Thomas, C. (2013). Traumatic brain injury and teacher training: A gap in educator preparation. Physical Disabilities: Education and Related Services, 32(1), 55-65.

Dettmer, J., Ettel, D., Glang, A., \& McAvoy, K. (2014). Building statewide infrastructure for effective educational services for students with TBI: Promising practices and recommendations. Journal of Head Trauma Rehabilitation, 29(3), 224-232. doi:10.1097/HTR.0b013e3182a1cd68

Dise-Lewis, J. E., Lewis, H. C., \& Reichardt, C. S. (2009). BrainSTARS: Pilot data on a team-based intervention program for students who have acquired brain injury. Journal of Head Trauma Rehabilitation, 24(3), 166-177. doi:10.1097/HTR.0b013e3181a7ecb0

Dyches, T. \& Prater, M. (2010). Disproportionate representation in special education: Overrepresentation of selected subgroups. In A. Rotatori (Series Ed.), Advances in Special Education: Vol. 19. Current issues and trends in special education: Identification, assessment and instruction (pp. 53-71). doi:10.1108/S0270-4013(2010)0000019007

Eisenberg, M. A., Andrea, J., Meehan, W., \& Mannix, R. (2013). Time interval between concussions and symptom duration. Pediatrics, 132. doi:10.1542/peds.2013-0432

Ettel, D., McCart, M., \& Glang, A. (2014). Textbook review: Traumatic brain injury in teacher education texts. Retrieved from http://media.cbirt.org/uploads/files/textbook_review.pdf

Evans, K., Hux, K., Chleboun, S., Goeken, T., \& Deuel-Schram, C. (2009). Persistence of brain injury misconceptions among speech language pathology graduate students. Contemporary Issues in Communication Science \& Disorders, 36, 166-173.

Farmer, J. E., Clippard, D. S., \& Luehr-Wiemann, Y. (1996). Assessing children with traumatic brain injury during rehabilitation: Promoting school and community reentry. Journal of Learning Disabilities, 29, 532-548. doi:10.1177/002221949602900508

Farmer, J. E., \& Johnson-Gerard, M. (1997). Misconceptions about traumatic brain injury among educators and rehabilitation staff: A comparative study. Rehabilitation Psychology, 42(4), 273-286. doi:10.1037/0090-5550.42.4.273

Faul, M., Xu, L., Wald, M., \& Coronado, V. (2010). Traumatic brain injury in the United States: Emergency department visits, hospitalizations and deaths 2002-2006. Atlanta, GA: Centers for Disease Control and Prevention, National Center for Injury Prevention and Control. 
Ganesalingam, K., Yeates, K. O., Taylor, H. G., Walz, N. C., Stancin, T., \& Wade, S. (2011). Executive functions and social competence in young children 6 months following traumatic brain injury. Neuropsychology, 25(4), 466-476. doi:10.1037/a0022768

Gerrard-Morris, A., Taylor, H. G., Yeates, K. O., Chertkoff Walz, N., Stancin, T., Minich, N., \& Wade, S. L. (2010). Cognitive development after traumatic brain injury in young children. Journal of the International Neuropsychological Society, 16(1), 157-168. doi:10.1017/s1355617709991135

Glang, A., Ettel, D., Todis, B., Gordon, W., Oswald, G., Vaughn, S., ... Brown, M. (2015). Services and supports for students with traumatic brain injury: Survey of state educational agencies, Exceptionality, 23(4), 211-224, doi:10.1080/09362835.2014.986612

Glang, A., Sohlberg, M. M., \& Todis, B. (1999). Making the IEP process work for students with brain injuries. Wake Forest, NC: L\&A.

Glang, A., Todis, B., Ettel, D., \& Yeates, K. (2013). Connecting hospitals and schools following pediatric brain injury. Paper presented at the 121st American Psychological Association Annual Convention, July 31-August 4, Honolulu, HI.

Glang, A., Todis, B., Sublette, P., Eagan-Brown, B., \& Vaccaro, M. (2010). Professional development in TBI for educators: The importance of context. Journal of Head Trauma Rehabilitation, 25(6), 426-432. doi:10.1097/HTR.0b013e3181fb8f45

Glang, A., Tyler, J., Pearson, S., Todis, B., \& Morvant, M. (2004). Improving educational services for students with TBI through statewide consulting teams. NeuroRehabilitation, 19(3), 219-231.

Glang, A., Ylvisaker, M., Stein, M., Ehlhardt, L., Todis, B., \& Tyler, J. (2008). Validated instructional practices: Application to students with traumatic brain injury. Journal of Head Trauma Rehabilation, 23(4), 243-251. doi:10.1097/01.HTR.0000327256.46504.9f

Guo, Y., Connor, C., Yang, Y., Roehrig, A., \& Morrison, F. (2012). The effects of teacher qualification, teacher self-efficacy, and classroom practices on fifth graders' literacy outcomes. Elementary School Journal, 113(1), 3-24.

Halstead, M. E., McAvoy, K., Devore, C. D., Carl, R., Lee, M., \& Logan, K. (2013). Returning to learning following a concussion. Pediatrics, 132(5), 948-957. doi:10.1542/peds.2013-2867

Hooper, S. R. (2006). Myths and misconceptions about traumatic brain injury: Endorsements by school psychologists. Exceptionality, 14(3), 171-182.

Hux, K., Bush, E., Evans, K., \& Simanek, G. (2013). Misconceptions about traumatic brain injury among students preparing to be special education professionals. Support for Learning, 28(3), 109-114. doi:10.1111/1467-9604.12028

Hux, K., Walker, M., \& Sanger, D. D. (1996). Traumatic brain injury: Knowledge and selfperceptions of school speech-language pathologists. Language, Speech, and Hearing Services in Schools, 27(2), 171-184.

Individuals with Disabilities Education Act, PL 101-476 C.F.R. $§ 20$ U.S.C. secs. 1400 et seq. (1990).

Iverson, G. L., Brooks, B. L., Collins, M. W., \& Lovell, M. R. (2006). Tracking neuropsychological recovery following concussion in sport. Brain Injury, 20(3), 245-252.

Kurowski, B. G., Taylor, H. G., Yeates, K. O., Walz, N. C., Stancin, T., \& Wade, S. L. (2011). Caregiver ratings of long-term executive dysfunction and attention problems after early childhood traumatic brain injury: Family functioning is important. $P M \& R, 3(9), 836-845$. doi:10.1016/j.pmrj.2011.05.016

Linden, M. A., Braiden, H.-J., \& Miller, S. (2013). Educational professionals' understanding of childhood traumatic brain injury. Brain Injury, 27(1), 92-102. doi:10.3109/02699052.2012.722262 
Moser, R. S., Schatz, P., \& Jordan, B. D. (2005). Prolonged effects of concussion in high school athletes. Neurosurgery, 57(2), 300-306; discussion 300-306.

Rimel, R. W., Giordani, B., Barth, J. T., Boll, T. J., \& Jane, J. A. (1981). Disability caused by minor head injury. Neurosurgery, 9(3), 221-228.

Rivara, F. P., Koepsell, T. D., Wang, J., Temkin, N., Dorsch, A., Vavilala, M. S., ... Jaffee, K. M. (2012). Incidence of disability among children 12 months after traumatic brain injury. American Journal of Public Health, 102(11), 2074-2079. doi:10.2105/ajph.2012.300696

Rivara, F. P., Vavilala, M. S., Durbin, D., Temkin, N., Wang, J., O’Connor, S. S., ... Jaffee, K. M. (2012). Persistence of disability 24 to 36 months after pediatric traumatic brain injury: A cohort study. Journal of Neurotrauma, 29(15), 2499-2504. doi:10.1089/neu.2012.2434

Sesma, H. W., Slomine, B. S., Ding, R., McCarthy, M. L., \& the Children's Health After Trauma Study Group. (2008). Executive functioning in the first year after pediatric traumatic brain injury. Pediatrics, 121(6), 1686-1695. doi:10.1542/peds.2007-2461

Taylor, H. G., Yeates, K. O., Wade, S. L., Drotar, D., Stancin, T., \& Montpetite, M. (2003). Longterm educational interventions after traumatic brain injury in children. Rehabilitation Psychology, 48(4), 227-236. doi:10.1037/0090-5550.48.4.227

Telzrow, C. F. (1987). Management of academic and educational problems in head injury. Journal of Learning Disabilities, 20(9), 536-545.

Todis, B., \& Glang, A. (2008). Redefining success: Results of a qualitative study of postsecondary transition outcomes for youth with traumatic brain injury. Journal of Head Trauma Rehabilitation, 23(4), 252-263. doi:10.1097/01.HTR.0000327257.84622.bc

Todis, B. P., Glang, A. P., Bullis, M. P., Ettel, D. P., \& Hood, D. B. A. (2011). Longitudinal investigation of the post-high school transition: Experiences of adolescents with traumatic brain injury. Journal of Head Trauma Rehabilitation, 26(2), 138-149. doi:10.1097/HTR.0b013e3181e5a87a

Turnbull, A., Turnbull, R., Wehmeyer, M. L., \& Shogren, K. A. (Eds.). (2013). Exceptional lives: Special education in today's schools (7th ed.). Boston, MA: Pearson.

U.S. Department of Education National Center for Education Statistics. (2015). Digest of Education Statistics, 2013 (NCES 2015-011), Table 204.30. Retrieved from https://nces.ed.gov /fastfacts/display.asp?id $=64$

Walz, N. C., Cecil, K. M., Wade, S. L., \& Michaud, L. J. (2008). Late proton magnetic resonance spectroscopy following traumatic brain injury during early childhood: Relationship with neurobehavioral outcomes. Journal of Neurotrauma, 25(2), 94-103. doi:10.1089/neu.2007.0362

Willer, B., \& Leddy, J. J. (2006). Management of concussion and post-concussion syndrome. Current Treatment Options In Neurology, 8(5), 415-426.

Yeates, K. O. (2010). Mild traumatic brain injury and postconcussive symptoms in children and adolescents. Journal of the International Neuropsychological Society, 16, 953-960. doi:10.1017/S1355617710000986

Yeates, K. O., Armstrong, K., Janusz, J., Taylor, H. G., Wade, S., Stancin, T., \& Drotar, D. (2005). Long-term attention problems in children with traumatic brain injury. Journal of the American Academy of Child and Adolescent Psychiatry, 44(6), 574-584.

Ylvisaker, M., Adelson, P. D., Braga, L. W., Burnett, S. M., Glang, A., Feeney, T., ... Todis, B. (2005). Rehabilitation and ongoing support after pediatric TBI: Twenty years of progress. Journal of Head Trauma Rehabilitation, 20(1), 95-109.

Ylvisaker, M., \& Feeney, T. J. (1998). Collaborative brain injury intervention: Positive everyday routines. San Diego, CA: Singular Publishing Group 
Ylvisaker, M., Todis, B., Glang, A., Urbanczyk, B., Franklin, C., DePompei, R., ... Tyler, J. S. (2001). Educating students with TBI: Themes and recommendations. Journal of Head Trauma Rehabilitation, 16(1), 76-93.

Zaloshnja, E., Miller, T., Langlois, J. A., \& Selassie, A. W. (2008). Prevalence of long-term disability from traumatic brain injury in the civilian population of the United States, 2005. Journal of Head Trauma Rehabilitation, 23(6), 394-400. doi:10.1097/01.HTR.0000341435.52004.ac

\section{Authors' Note}

Correspondence concerning this article should be addressed to Deborah Ettel, 2750 Capital Drive, Eugene, OR, 97403, USA. Email: drdeb2009@gmail.com

\section{Appendix}

\section{TBI Knowledge Survey}

\section{Your Current Area of Teaching:}

General Education

Special Education

Current Grade(s) Taught (select all that apply):

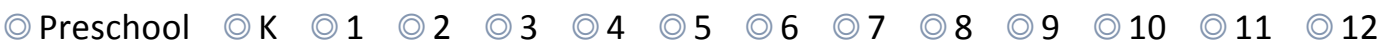

Highest Degree Earned:

() Bachelor's () Master's () Doctorate

Date Highest Earned:

Before 1970

(a) $1970-80$

$1981-90$

$1991-2000$

$2001-2010$

Areas of certification(s)/license(s) held:

General Education

Special Education

Were you trained or are you being trained in traumatic brain injury (TBI)?
YES
NO 
If YES, describe what kind of training you have received [check all that apply]:

() Class/seminar specifically devoted to TBI?

() Survey class on disabilities?

(a) Workshop (half-day or more)?

() In-service/professional development seminar?

Other Training (if applicable)

Please list any TBI resources that were used in your training (e.g., websites, books, training manuals, etc.):

\section{Teaching Experience}

Years of teaching experience:
(2) 0-5
(a) 6-10
11-15
(2) $16-20$
$21-25$
(2) $26+$

Approximately how many students with TBI have you worked with in a school setting?
(2) none (0)
(a) few (1-5)
() several (6-10)
(2) many $(>11)$

\section{Personal Experience}

Do you have a close friend or family member who has ever sustained a:

$\begin{array}{lcc} & \text { YES } & \text { NO } \\ \text { Concussion/mild brain injury } & 0 & 0 \\ \text { Moderate- severe brain injury } & ( & 0\end{array}$

Have you ever sustained a:

$\begin{array}{lcc} & \text { YES } & \text { NO } \\ \text { Concussion/mild brain injury } & 0 & 0 \\ \text { Moderate- severe brain injury } & ( & 0\end{array}$




\section{Section 1}

Please mark True, Probably True, Probably False, or False

Probably
True
Truebably False

1. TBI is equally common in males and females.
2. A child/adolescent in a coma is usually not aware of
what is happening around them.

4. A brain injury affects girls' and boys' brains differently.

5. Even after several weeks in a coma, when children/adolescents wake up, most recognize and speak to others right away.

6. After a brain injury, it is usually harder to learn new things than it is to remember things from before the injury.

7. A child/adolescents 's pre-injury status (i.e., intellectual and emotional functioning) is likely to impact recovery from brain injury.

8. Children/adolescents who have had one brain injury are more likely to have a second one.

9. Complete recovery from severe brain injury is not possible no matter how badly the child/adolescent wants to recover.

10. Children/adolescents are likely to recover more completely from a brain injury than adults due to the greater plasticity of the young brain.

11. A child who acquires a brain injury between 12 and 16 will typically present an even pattern of academic strengths and weaknesses.

12. A child's brain, unlike an adult's, is able to "bounce back" after a brain injury.

13. It is common for children/adolescents with brain injuries to be easily angered.

14. Fluctuation among cognitive abilities is a finding typical of children and adolescents who have a brain injury, and not typical of the general population of children and adolescents.

15. When children/adolescents are knocked unconscious, most wake up quickly with no lasting effects. 
Section 1, continued

Please mark True, Probably True, Probably False, or False

$\begin{array}{cc}\text { True } & \begin{array}{c}\text { Probably } \\ \text { True }\end{array} \\ \text { False } & \text { False }\end{array}$

16. It is important to provide many details when delivering instructions to a student with brain injury.

17. Greater variability exists in the population of students with TBI than exists in populations of other students with disabilities.

18. The only sure way to tell if someone has suffered brain impairment from a brain injury is by an X-ray of the brain.

19. Knowing the location of brain injury resulting from TBI helps in the development of programming to meet a student's needs.

20. Many students with TBI display characteristics similar to those of students with a learning disability.

21. Knowledge of a student's background prior to TBI is necessary when developing an educational plan.

22. Medical labels that specify TBI as mild, moderate, or severe are useful for programming communication and academic services.

23. The primary goal of brain injury rehabilitation is to increase physical abilities such as walking.

24. Many students with TBI perform better in structured testing situations than they do in classroom settings.

25. The challenges of students with TBI are typically more difficult to assess than the challenges of students with other disabilities.

26. Most special and regular educators are knowledgeable about the speech, language, and cognitive communication problems associated with TBI.

27. Students with TBI often have trouble forming and maintaining friendships.

28. Recovery following TBI may continue for several years.

29. Students with TBI often display behavior problems.

(2) (2) (2)

())

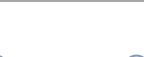

()

(c)

(2)

.

(9)

(2)

(a) (a) (a)




\section{Section 2}

Below are four different scenarios you might encounter in the classroom. For each scenario, consider that the child in question has CONSISTENTLY shown the described behavior and it is NOT an isolated event. The child may have been identified as having had a traumatic brain injury (TBI) or you suspect that he/she may have had a TBI. Please rate how likely you are to respond in each possible response. Score EACH response by how likely you would be to employ each action in the situation described.

1) Susan has difficulty paying attention in her 3rd grade class, especially in the afternoon. She is often caught daydreaming or is otherwise distracted but not disruptive. She sometimes complains of headaches. You could:

a. Reposition her desk to front of room so you can keep an eye on her and maintain her attention.

() Never () Fairly Unlikely () Somewhat Likely () Fairly Likely () Very Likely

b. Send a note home to her parents cautioning about the consequences of continued problem behavior.

() Never () Fairly Unlikely () Somewhat Likely () Fairly Likely () Very Likely

c. Consider referring her for ADHD testing.

() Never () Fairly Unlikely () Somewhat Likely () Fairly Likely () Very Likely

d. How confident are you that you could successfully handle a situation like this?

○ Not at all () Very Little () Somewhat () Very Confident () Completely Confident

2) All through middle school and now in 9th grade, Dave rarely hands in assignments on time, seldom gets to class before the bell rings and inevitably forgets to bring books or pencil to class. He has the ability to do average work but has problems initiating tasks. You could:

a. Take Dave's notebook and use a series of notes laminated in the notebook to outline the steps required for your class.

() Never () Fairly Unlikely () Somewhat Likely () Fairly Likely () Very Likely

b. Say: "You're in 9th grade now. Make sure you come prepared for class or you may end up in summer school." or similar warning of the consequences of continued disorganization.

() Never () Fairly Unlikely () Somewhat Likely () Fairly Likely () Very Likely

c. Conference with Dave and his parents to strategize how Dave can get to class on time and be prepared to participate now that he is in high school.
Never
Fairly Unlikely
Somewhat Likely
Fairly Likely
Very Likely

\section{d. How confident are you that you could successfully handle a situation like this?}

( ) Not at all () Very Little () Somewhat () Very Confident () Completely Confident 


\section{Section 2, continued}

3) Mary hits, shoves, or pushes peers and/or adults in her 8th grade classes with little or no provocation, and uses aggressive or threatening language. You could:

a. Teach Mary strategies for identifying impending anger or frustration and allow her to take inclass time-outs.

() Never () Fairly Unlikely () Somewhat Likely () Fairly Likely () Very Likely

b. Establish and explain clear rules for expected behavior and natural or logical consequences if the rules are not followed and consistently follow up on established consequences.

() Never (?) Fairly Unlikely () Somewhat Likely () Fairly Likely (?) Very Likely

c. Identify any "triggers" that seem to precede the aggressive behaviors and manage the environment to reduce those triggers.

() Never () Fairly Unlikely () Somewhat Likely () Fairly Likely () Very Likely

d. How confident are you that you could successfully handle a situation like this?

() Not at all () Very Little () Somewhat () Very Confident () Completely Confident

4) Phillip is in 11th grade and constantly speaks out of turn, shows off, or engages in other apparent attention-seeking behavior. It is often disruptive to classroom activities. You could:

a. Instruct other students to ignore the attention-seeking behaviors.

() Never (?) Fairly Unlikely (?) Somewhat Likely (?) Fairly Likely () Very Likely

b. Ensure that strategies are in place to enhance Phillip's self-esteem and self-concept (such as providing challenging and meaningful tasks) so he has less need to act out.

() Never () Fairly Unlikely () Somewhat Likely () Fairly Likely () Very Likely

c. Provide opportunities for him to work successfully with other students.

() Never (?) Fairly Unlikely () Somewhat Likely () Fairly Likely (?) Very Likely

d. How confident are you that you could successfully handle a situation like this?

() Not at all () Very Little () Somewhat () Very Confident () Completely Confident 